\title{
THE
}

\section{Aggregate Measures of Ecosystem Services: Can We Take the Pulse of Nature?}

\author{
Laura A. Meyerson \\ University of Rhode Island, lameyerson@uri.edu \\ Jill Baron \\ Jerry M. Melillo \\ Robert J. Naiman \\ Robin I. O'Malley
}

See next page for additional authors

Follow this and additional works at: https://digitalcommons.uri.edu/nrs_facpubs

Terms of Use

All rights reserved under copyright.

\section{Citation/Publisher Attribution}

Meyerson, L. A., Baron, J. , Melillo, J. M., Naiman, R. J., O'Malley, R. I., Orians, G. , Palmer, M. A., Pfaff, A. S., Running, S. W. and Sala, O. E. (2005), Aggregate measures of ecosystem services: can we take the pulse of nature?. Frontiers in Ecology and the Environment, 3: 56-59. doi:10.1890/

1540-9295(2005)003[0056:AMOESC]2.0.CO;2

Available at: http://dx.doi.org/10.1890/1540-9295(2005)003[0056:AMOESC]2.0.CO;2

This Article is brought to you for free and open access by the Natural Resources Science at DigitalCommons@URI. It has been accepted for inclusion in Natural Resources Science Faculty Publications by an authorized administrator of DigitalCommons@URI. For more information, please contact digitalcommons-group@uri.edu. 


\section{Authors}

Laura A. Meyerson, Jill Baron, Jerry M. Melillo, Robert J. Naiman, Robin I. O'Malley, Gordon Orians, Margaret A. Palmer, Alexander S. P. Pfaff, Steven W. Running, and Osvaldo E. Sala 


\section{ECOLOGICAL SOCIETY OF AMERICA}

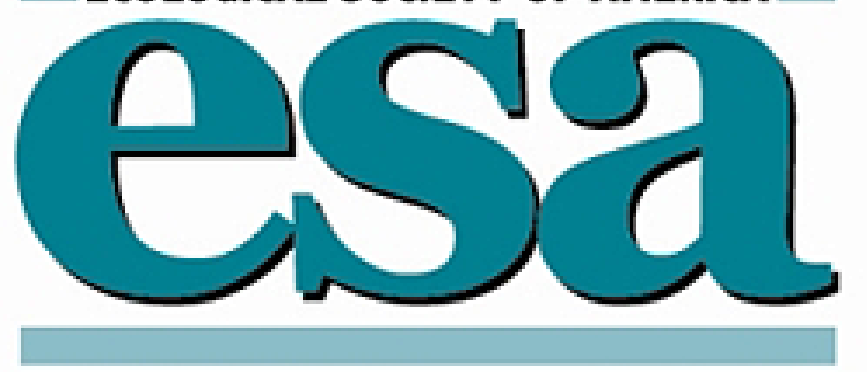

Aggregate Measures of Ecosystem Services: Can We Take the Pulse of Nature?

Author(s): Laura A. Meyerson, Jill Baron, Jerry M. Melillo, Robert J. Naiman, Robin I.

O'Malley, Gordon Orians, Margaret A. Palmer, Alexander S. P. Pfaff, Steven W. Running and Osvaldo E. Sala

Source: Frontiers in Ecology and the Environment, Vol. 3, No. 1, Visions for an Ecologically Sustainable Future (Feb., 2005), pp. 56-59

Published by: Ecological Society of America

Stable URL: http://www.jstor.org/stable/3868445

Accessed: $12 / 07 / 2013$ 12:58

Your use of the JSTOR archive indicates your acceptance of the Terms \& Conditions of Use, available at http://www.jstor.org/page/info/about/policies/terms.jsp

JSTOR is a not-for-profit service that helps scholars, researchers, and students discover, use, and build upon a wide range of content in a trusted digital archive. We use information technology and tools to increase productivity and facilitate new forms of scholarship. For more information about JSTOR, please contact support@jstor.org. 


\title{
Aggregate measures of ecosystem services: can we take the pulse of nature?
}

\author{
Laura A Meyerson ${ }^{1}$, Jill Baron ${ }^{2}$, Jerry M Melillo ${ }^{3}$, Robert J Naiman ${ }^{4}$, Robin I O’Malley ${ }^{1}$, Gordon Orians ${ }^{5}$, \\ Margaret A Palmer ${ }^{6}$, Alexander SP Pfaff ${ }^{7}$, Steven W Running ${ }^{8}$, and Osvaldo E Sala ${ }^{9}$
}

National scale aggregate indicators of ecosystem services are useful for stimulating and supporting a broad public discussion about trends in the provision of these services. There are important considerations involved in producing an aggregate indicator, including whether the scientific and technological capacity exists, how to address varying perceptions of the societal importance of different services, and how to communicate information about these services to both decision makers and the general public. Although the challenges are formidable, they are not insurmountable. Quantification of ecosystem services and dissemination of information to decision makers and the public is critical for the responsible and sustainable management of natural resources.

Front Ecol Environ 2005; 3(1): 56-59

$B^{y}$ the middle of the 19th century, prominent naturalists and ecologists, including George Perkins Marsh, Aldo Leopold, Fairfield Osborn, and Paul Sears, recognized the "life-support" functions of ecosystems. The term "environmental services" was first used in 1970 to describe well-functioning ecosystems and the benefits people

\section{In a nutshell:}

- The ability to report trends in the quantity of ecosystem services is critical to knowing whether or not these natural resources are being used sustainably

- A national-level indicator of ecosystem services could allow policy makers, scientists, and the public to understand whether the US is gaining or losing critical services and to have an informed debate about what the response to those changes should be

- Development of a national indicator of ecosystem services is a major challenge; success will require collaboration among ecologists, economists, statisticians, policy makers, and other stakeholders, but such an effort could ultimately provide invaluable guidance on the responsible and sustainable management of our natural resources

${ }^{1}$ The H John Heinz III Center for Science, Economics and the Environment, 1001 Pennsylvania Avenue, NW, Washington, DC (meyerson@heinzctr.org); ${ }^{2} U S$ Geological Survey, Natural Resource Ecology Laboratory, Colorado State University, Fort Collins, CO; ${ }^{3}$ The Marine Biological Laboratory, Woods Hole, MA; ${ }^{4}$ University of Washington, Aquatic and Fishery Sciences, Seattle, WA; ${ }^{5}$ Department of Biology, University of Washington, Lake Forest Park, WA; ${ }^{6}$ Plant Sciences Bldg 4112, University of Maryland, College Park, MD; ${ }^{7}$ School of International and Public Affairs, Dept of Economics, Columbia University, New York, NY; ${ }^{8}$ Numerical Terradynamic Simulation Group, Dept of Ecosystem and Conservation Sciences University of Montana, Missoula, MT; ${ }^{9}$ Dept of Ecology, Universidad de Buenos Aires, Catedra de Ecol, Fac de Agro, Buenos Aires, Argentina. receive from them, such as food, pest control, flood control, climate regulation, and recreation (SCEP 1970). These benefits are central to human well-being, yet it is unclear whether they are sustainable at current or projected use levels. As highlighted in this special issue of Frontiers, we face enormous environmental challenges that are expected to increase in the 21 st century.

Quantifying and monitoring the flows of ecosystem services is critical, yet the scale at which services can and should be reported is a matter of serious debate. Ecosystem services are often provided locally or regionally (Figure 1). A national reporting system for those services that we are currently able to quantify would require aggregation at multiple scales. One option is to develop a national-level aggregate indicator of ecosystem services, an indicator that would command public attention, just as today's economic indicators do (eg gross national product, inflation). However, the national economy is reasonably connected, or "well mixed", and therefore lends itself better to a single aggregate indicator such as GNP. In contrast, ecosystems across the country are not necessarily connected. The ecological conditions in Florida are not closely related to the same indicator variables in Montana. Consequently, a geographically explicit mapping of our ecosystem services indicator will clarify the regional nature of the services and the scales at which they are occurring.

An ecosystem services indicator could not be all-inclusive; we would therefore need to make decisions about which services to include, how each should be weighted, and how to characterize the tradeoffs between services. Like the economic indicators, an ecosystem services indicator would convey concise information on large-scale trends in ecosystem services, although it could not by itself provide all of the information necessary to make specific policy decisions. Despite these limitations, such an indicator would be useful and is greatly needed to pro- 


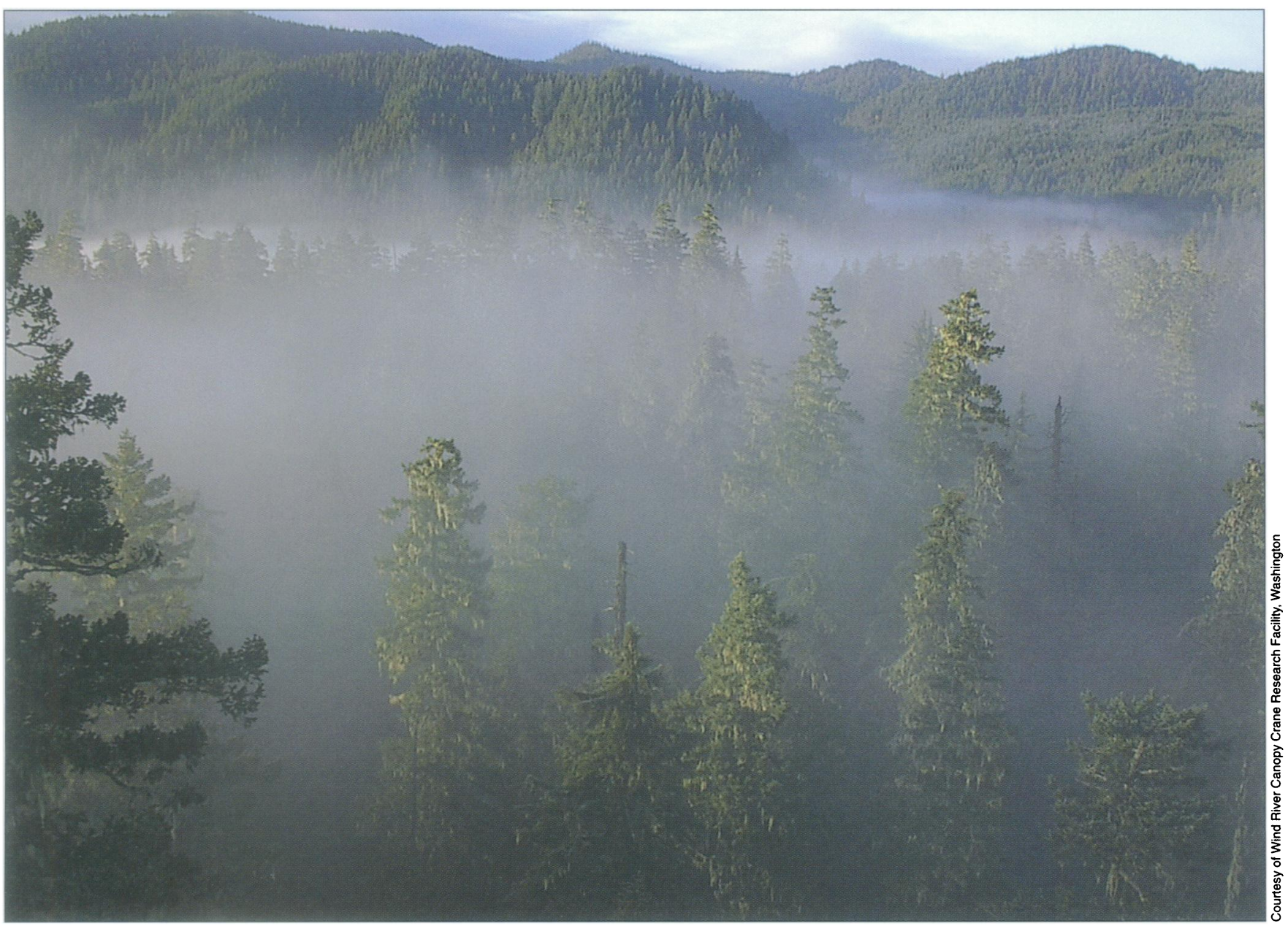

Figure 1. Forested watersheds provide many ecosystem services, some quantifiable, others more difficult to assess. Climate moderation, carbon and nutrient storage, water purification and supply, recreation, habitat, forest products, and genetic reservoirs are just some of the services possibly captured by a national aggregate ecosystem services indicator.

vide a focus for broad discussions on whether the nation is gaining or losing services and how to respond to such changes if they occur, just as changes in unemployment are greeted with analysis and recommendations by the economic and fiscal policy community.

Thus, our goal is to stimulate research and dialogue on the feasibility and form of a national indicator of ecosystem services. Here, we briefly review progress to date and then highlight the remaining challenges.

Over the past decade, ecosystem services have been the subject of several important assessments and are an area of active research. Recent work by the Millennium Ecosystem Assessment (MA; www.millenniumassess ment.org) used a taxonomy with four major categories of services - provisioning, regulating, cultural, and supporting. When humans manage ecosystems to maximize certain benefits, other services may decline as a consequence. The MA examined some of the tradeoffs among individual ecosystem services as well as the tradeoffs between the four different categories of services that it described (MA 2003). The MA and a number of other initiatives (eg Daily 1997; Costanza et al. 1997; Harwell et al. 1999; NRC 2000) have provided a crucial foundation for the science of ecosystem services and the communication of their importance to the public.

The State of the Nation's Ecosystems report (The Heinz Center 2002) recognized the quantification of ecosystem services as essential to evaluating the condition of major US biomes. However, measuring and aggregating the status of services other than food, fiber, water, and recreation proved to be a daunting task. The report acknowledged that reaching agreement on aggregating services such as nitrogen removal or plant pollination would be difficult and would require filling many gaps in our knowledge. Therefore, a three-part strategy was developed: to report on the extent of ecosystems (more forest generally means more forest-oriented services), to report on the condition of ecosystems (higher levels of soil erosion can reduce productivity), and to report on the quantities of some flows of ecosystem-oriented goods (food, fiber, water). This approach left readers to discern for themselves whether the nation's ecosystems were providing more or fewer services overall.

Currently, we can quantify the capacity of ecosystems to provide certain services (eg soil organic matter formation, net primary productivity). We can measure other 
components also, including the few that have market values (eg water provisioning, recreation). There has been noteworthy success at local scales to monetize many benefits of ecosystem services (eg Catskills water management for New York City and the Working for Water Programme in South Africa). This represents important progress, but does not fully address the feasibility of developing a simple, multi-term equation that will yield a single aggregate indicator of ecosystem services. Producing an aggregate indicator presents unique challenges and considerations including whether the scientific and technological capacity exists, how to address varying perceptions of the societal importance of different services, and how to communicate information about these services to both decision makers and the general public.

Parameterization of an aggregate indicator will probably necessitate a number of metrics, requiring difficult choices every step of the way. The terms used to create this indicator formula would ideally be value-free, but in reality they will reflect the values of those making the decisions. Criteria for inclusion of terms must be determined, but they clearly should not be prescriptive (eg there is no "right" level of productivity), should collectively address a broad range of services, and must be able to be explained and defended before a wide variety of audiences. Some

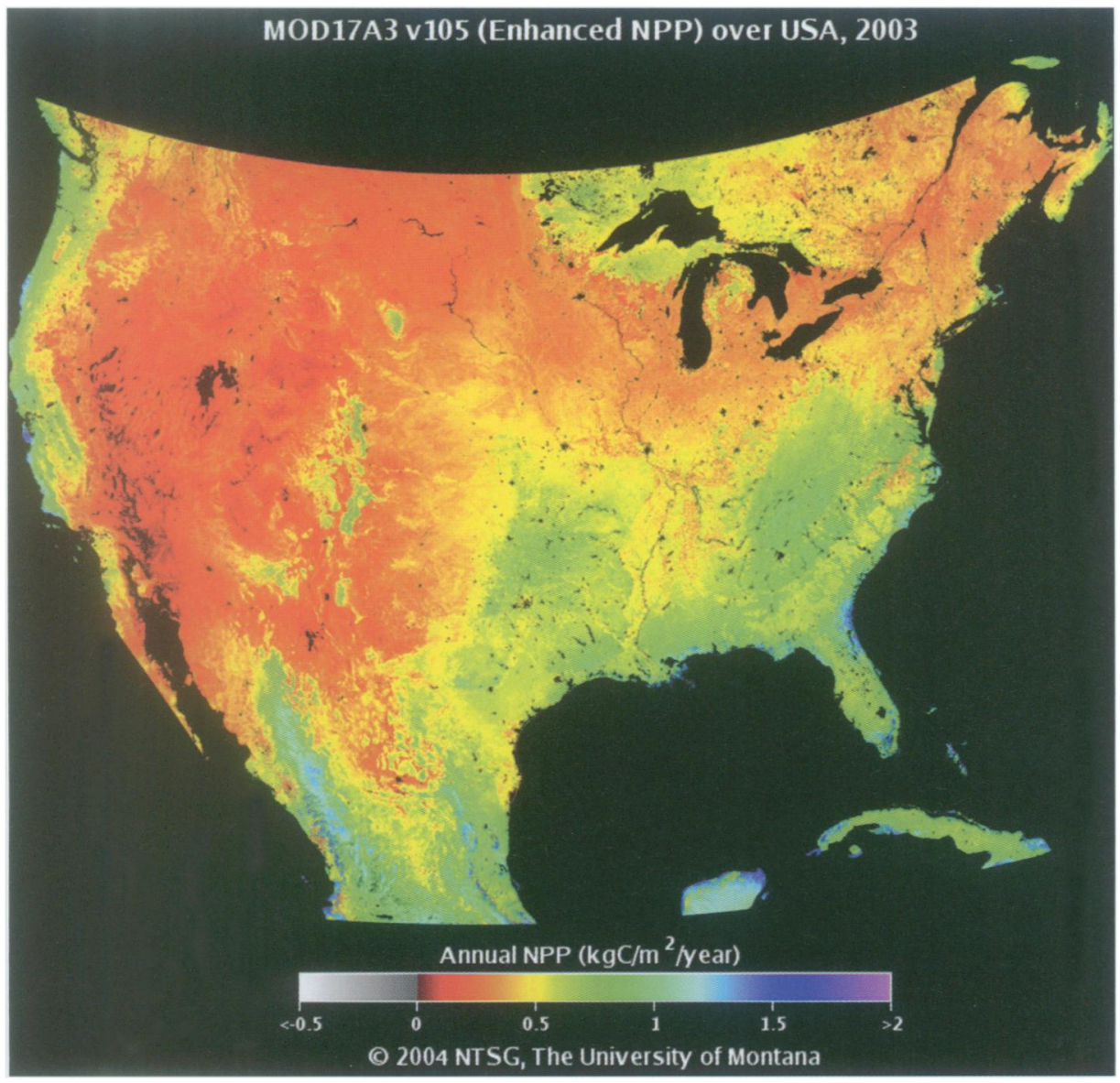

Figure 2. Net primary production (NPP) for the US for 2003. Some parameters for an aggregate index of ecosystem services, such as NPP, are relatively easy to assess for the entire US, while services are more regionally or locally specific. parameters would be relatively easy to quantify, and geographically explicit measures such as terrestrial net primary productivity (NPP) already are being produced for the country (Figure 2). Others are not so easily measured (eg aesthetic and recreational services) or provide complex, regionally specific benefits that we may not yet know how to assess (eg biodiversity; Figure 3). Any national indicator variable must be measured consistently across the entire country and should use monitoring designs that are scaleable, comparable, and statistically defensible. Such requirements will generate substantial methodological challenges.

Ecosystem services occur at various scales and are quantified by different metrics, making aggregation into a single equation dependent on creative and thoughtful scholarship (and unavoidable value judgments). Furthermore, the services included in the equation will need to be weighted relative to each other and to account for the tradeoffs of increasing one service at the expense of another. Water is much more valuable in the arid west than in the mesic northeast. Consequently, the "indicator equation" must have differential geographic weighting for different parts of the country. The indicator must be clear, concise, easily explained, and retain enough information to highlight the most important aspects of ecosystem services. A great deal of basic research - by ecologists, economists, statisticians, policy experts, and others - will be necessary for the creation of an aggregate indicator. We need to examine what is gained and what is lost through aggregation, in order to ensure that an aggregate indicator provides additional benefits that a suite of disaggregated measures will not.

The challenges associated with this task are formidable, but are not insurmountable. Today's widely accepted economic indicators were developed over decades, not days. The science of ecosystem services remains a major research challenge for our community, and we believe that the creation of an aggregate measure of ecosystem services is central to that process. Quantification of ecosystem services and communication of the information to decision makers and the public is critical to the responsible and sustainable management of natural resources. A concise, credible, and reliable reporting system is urgently required to meet this need. 


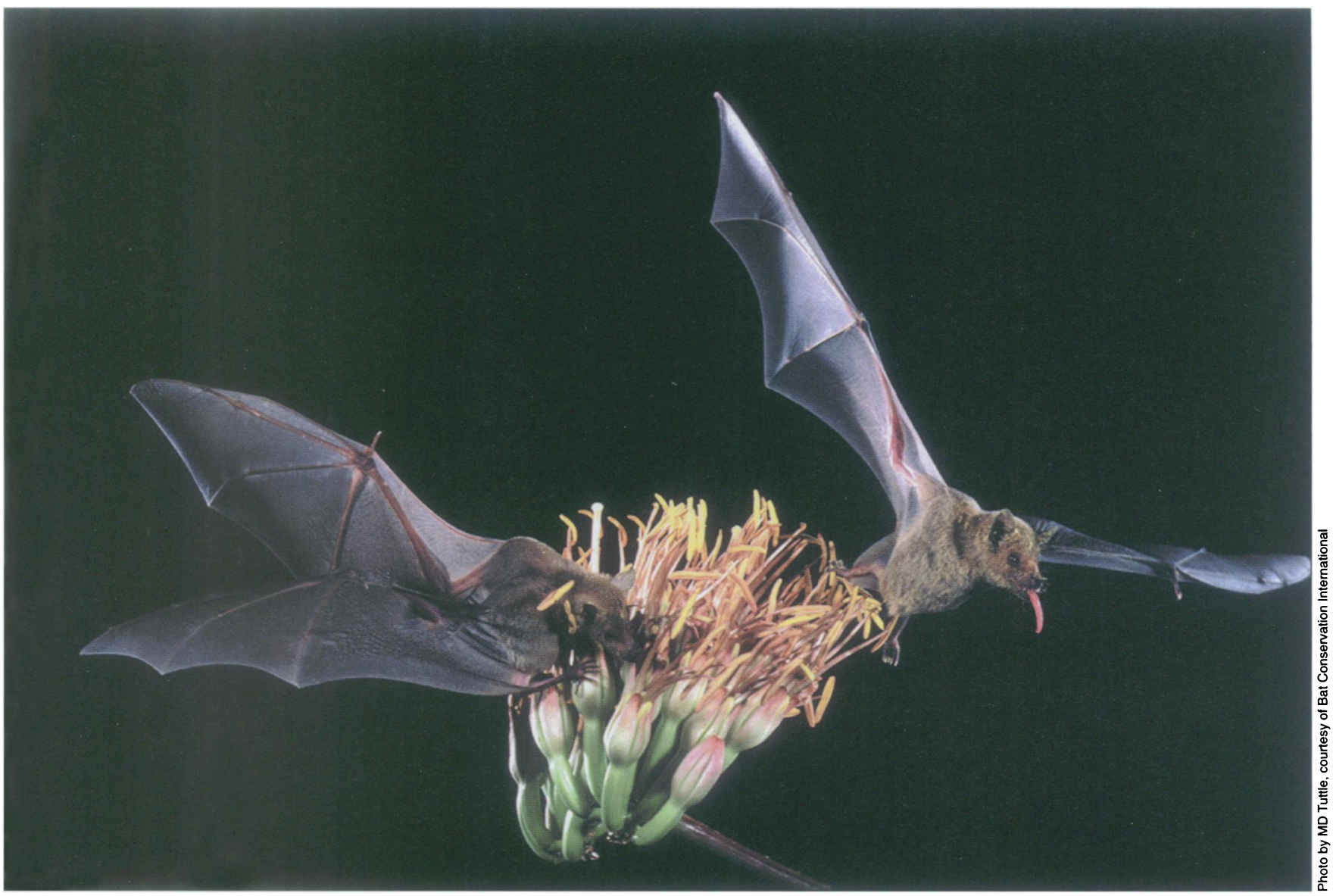

Figure 3. Long-nosed bats (Leptonycteris curasoae) and an agave plant. The flowers of this agave become reproductively active only at night, making this species so dependent on bats for pollination that seed-set drops to 1/3000th of normal in their absence. Bats that land to feed on the nectar become covered with pollen, and then carry it from flower to flower.

\section{Acknowledgements}

Many of the ideas in this manuscript emerged from a Heinz Center meeting hosted by the Marine Biological Laboratory in Woods Hole in June 2004. The participants were J Baron, K Cavender-Bares, W Clark, C Field, G Heal, C Kousky, J Melillo, L Meyerson, RJ Naiman, R O'Malley, G Orians, M Palmer, A Pfaff, S Running, O Sala, J Sarukhan, and G Woodwell.

\section{References}

Daily GC. (Ed). 1997. Nature's services. Societal dependence on natural ecosystems. Washington DC: Island Press.

Costanza R, d'Arge R, de Groot R, et al. 1997. The value of the world's ecosystem services and natural capital. Nature 387: 253-60.

Harwell MA, Myers V, Young T, et al. 1999. A framework for an ecosystem integrity report card. BioScience 49: 543-56.

MA (Millennium Ecosystem Assessment). 2003. Ecosystems and human well-being: a framework for assessment. Washington, DC: Island Press.

NRC (National Research Council). 2000. Ecological indicators for the nation. Washington, DC: National Research Council.

Running SW, Nemani RR, Heinsch FA, et al. (2004) A continuous satellite-derived measure of global terrestrial primary production. Bioscience 54: 547-60.

SCEP (Study of Critical Problems). 1970. Man's impact on the global environment. Cambridge, MA: MIT Press.

The Heinz Center. 2002. The State of the Nation's Ecosystems. New York, NY: Cambridge University Press (www.heinzctr. org/ecosystems). 